\title{
Molecular survey of head lice (Pediculus humanus capitis) infestation among disadvantaged children in Klang Valley, Malaysia
}

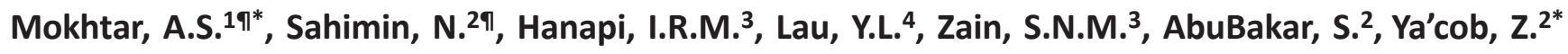 \\ ${ }^{1}$ Department of Microbiology, Faculty of Medicine, Manipal University College Malaysia, Jalan Batu Hampar, 75150 Bukit Baru, Melaka, Malaysia \\ ${ }^{2}$ Higher Centre of Excellence (HICOE), Tropical Infectious Diseases Research \& Education Centre (TIDREC), Universiti Malaya, 50603 Kuala Lumpur, \\ Malaysia \\ ${ }^{3}$ Institute of Biological Sciences, Faculty of Science, Universiti Malaya, 50603 Kuala Lumpur, Malaysia \\ ${ }^{4}$ Department of Medical Microbiology, Faculty of Medicine, Universiti Malaya, 50603 Kuala Lumpur, Malaysia \\ IThese authors contributed equally to this work \\ *Corresponding authors: syafinaz.mokhtar@manipal.edu.my; zyacob@um.edu.my
}

\section{ARTICLE HISTORY}

Received: 22 September 2021 Revised: 2 December 2021 Accepted: 2 December 2021 Published: 31 December 2021

\begin{abstract}
Ectoparasitic infestations including pediculosis capitis are common in people of disadvantaged communities as they live in overcrowded institutions, a condition that often favourable for disease transmission. In this study, we evaluated the prevalence of head lice infestation among disadvantaged children aged between five to 14 years-old living in five poor conditions located across the Klang Valley, Malaysia. Of total 335 children examined, $14 \%$ were positively infected with head lice. Molecular analysis using the universal cytochrome c oxidase subunit I (COI) barcoding gene on total of 167 head lice collected in this study indicated they are belonging to the $A$ and $C$ clades; confirming the global distribution of clade $A$ and expansion of clade $C$ in Southeast Asia, which is reported for the first time in Malaysia.
\end{abstract}

Keywords: COI; DNA barcoding; disadvantaged children; head lice; Malaysia.

\section{INTRODUCTION}

Infestation by head lice is termed pediculosis capitis and it commonly affects younger age groups worldwide, particularly among those living in densely-packed conditions (Falagas et al., 2008; Nutanson et al., 2008). Epidemiological studies have been conducted to access the prevalence of pediculosis capitis in Malaysian children since 1981 (Sinniah et al., 1981; Sinniah et al., 1983; Bachok et al., 2006; Muhammad Zayyid et al., 2010; Yap et al., 2010) however, information of genetic diversity of head lice remains scanty. In Malaysia, children welfare institutions are mostly non-profitable and they often rely on public donations to fund and sustain their operations. Insufficient funding hinders adequate care for the occupants and lack of awareness further contributes to unhygienic practices in the premises. Therefore, this study aims to screen the prevalence of pediculosis capitis and their genetic diversity amongst disadvantaged children inhabiting Klang Valley's areas, where pediculosis infestation is likely to occur.

\section{MATERIALS AND METHODS}

The protocol involving human subjects was approved by the University of Malaya Medical Centre Ethics Committee (MEC Reference Number: 20201210-9589) and all participants provided written consent for this study.
Head lice sampling was conducted in Klang Valley, Malaysia from July 2019 to February 2020. Five welfare homes sheltering orphans, neglected children and refugees were randomly selected to represent the appropriate host population. Occupants were examined for the presence of head lice and pediculosis capitis is confirmed when living adults, nymphs or viable nits is detected. Head lice were collected from the host and directly transferred into microcentrifuge tube containing $70 \%$ alcohol; as preservative. All specimens were brought back to the laboratory for further processing.

DNA barcoding (Ratnasingham \& Hebert, 2013) was employed to determine the clade of the head lice specimens. Head lice DNA was extracted from the whole specimen using the GeneJET Genomic DNA purification kit (Thermo Fisher Scientific, Lithuania). The $\mathrm{COI}$ partial sequences were amplified according to Sunantaraporn et al. (2015). Cycle sequencing were performed by Apical Scientific Sdn. Bhd. (Selangor, Malaysia) using the forward primer. The COI DNA barcodes obtained were aligned with representative Barcode Index Numbers (BINs) of five clades; AAA1556 (Clade A), AAA1557 (Clade B), AAA1558 (Clade C), AAW5034 (Clade D) and ACR6059 (Clade E) using BioEdit Sequence Alignment Editor Software, Version 7.2.6 (Hall, 1999). The pairwise genetic distances for $\mathrm{COl}$ were computed using Kimura 2-parameter 
method and Maximum Likelihood (ML) phylogenetic tree was constructed in MEGA X version 10.2.6 (Kumar et al., 2018).

\section{RESULTS}

A total of 167 head lice were collected from 47 (14\%) out of overall 335 children participants aged five to 14 years old examined in this study.

$\mathrm{ML}$ analysis of the $168 \mathrm{CO}$ barcodes has revealed the genetic diversity of head lice in this study belonging to Pediculus humanus capitis corresponding with two clades: clade A (BOLD: AAA1556) and clade C (BOLD: AAA1558), as shown in Figure 1. K2P model calculation results using MEGA $X$ showed that intra- and inter-specific genetic distance exists obvious difference. The intra-specific K2P divergence averaged $0.005 \%$ for clade $A$ and $0.003 \%$ for clade $C$ whereas the interspecific K2P divergence between the two clades averaged $0.079 \%$. The inter-specific divergence value was greater than intra-specific values, more than 15 times.

Representative $\mathrm{CO}$ barcodes discovered in this study were assigned GenBank accession numbers: OK175617 and OK175618 for clade A; and OK175619 for clade C.

Four shelters presented head lice belonging to clades $A$ and $\mathrm{C}$ and one shelter (Ahmadiah Refugee Committee) had the occurrence of only clade $C$ head lice. In addition, the occurrence of two clades within the same individual were detected in occupants from three shelters.
The prevalence of pediculosis capitis among occupants and the occurrence of clades $A$ and $C$ in the five welfare homes are summarized in Table 1.

\section{DISCUSSION}

Pediculosis capitis remains a health issue throughout the world and Malaysia is no exception to this problem. High prevalence of pediculosis capitis especially amongst children is attributable to various factors including crowded living condition (Nutanson et al., 2008) and poor hygiene practices (Mokhtar et al., 2019). Despite the vector status of head lice in the transmission of pathogens to humans is not fully understood, there are increasing reports on the detection of pathogenic bacteria in head lice. Acinetobacter baumannii (Bouvresse et al., 2011; Kempf et al., 2012; Sunantaraporn et al., 2015; Mokhtar et al., 2019; Abd Majid et al., 2020), Bartonella recurrentis (Boutellis et al., 2013; Amanzougaghene et al., 2016), Bartonella quintana (Sasaki et al., 2006; Bonilla et al., 2009; Angelakis et al., 2011) and Serratia marcescens (Mokhtar et al., 2019) are amongst human pathogens that have been reported in the literature, suggesting head lice as a potential environmental reservoir posing a health threat to the infested children.

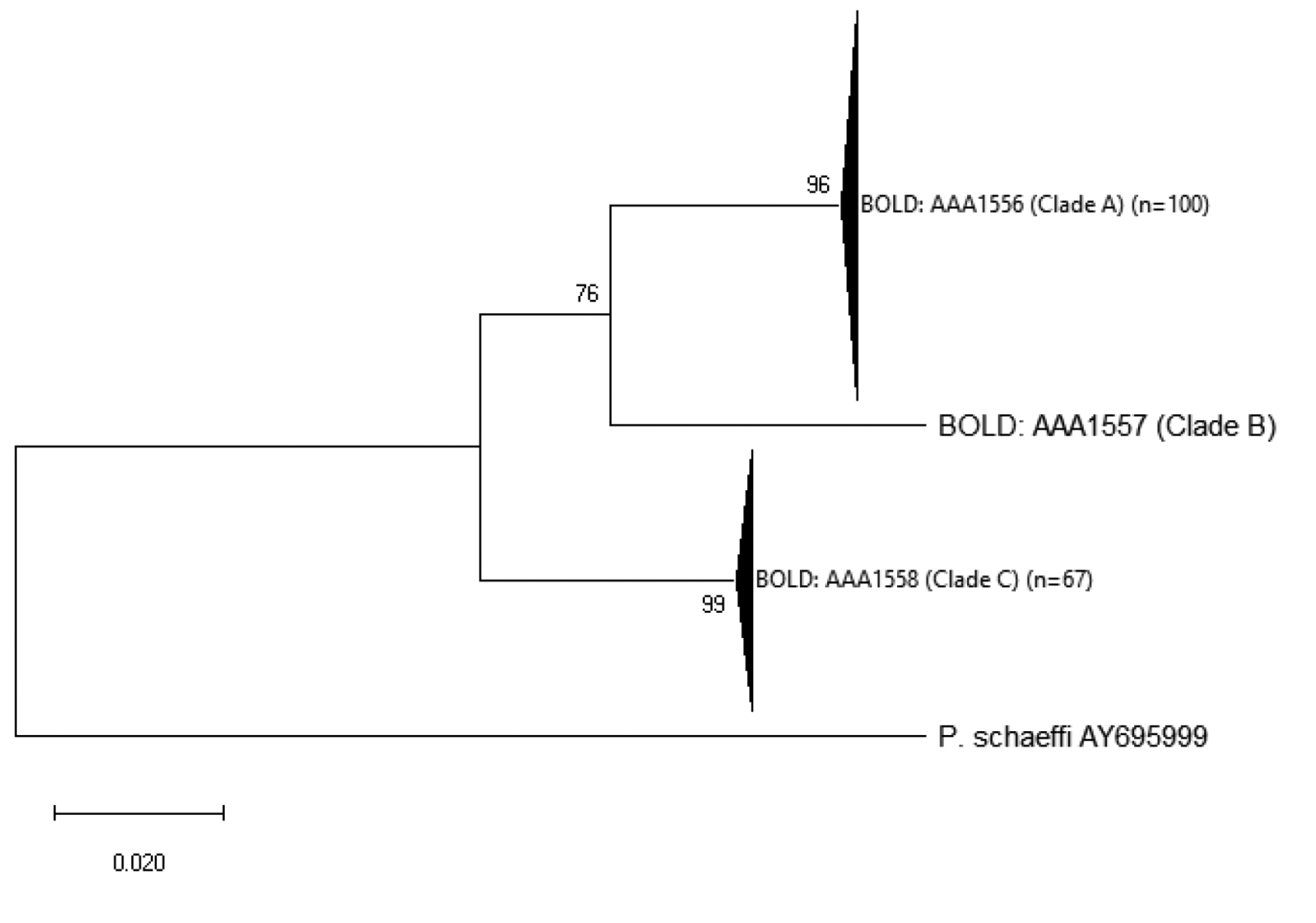

Figure 1. Maximum Likelihood (ML) phylogram of the COI barcodes showing the placement of the 167 head lice into two BINs of Clade A and C. The tree is drawn to scale, with branch lengths measured in the number of substitutions per site. Selected subtrees were compressed for visual reasons. Pediculus schaeffi (Accession Number: AY695999) was used as an outgroup. 
Table 1. Prevalence of pediculosis capitis and occurrence of clades A and C head lice in welfare homes in Klang Valley

\begin{tabular}{|c|c|c|c|c|c|c|c|c|}
\hline & \multirow{2}{*}{ City } & \multirow{2}{*}{ Welfare homes } & \multirow{2}{*}{$\begin{array}{l}\text { No. of } \\
\text { occupants } \\
\text { examined }\end{array}$} & \multirow{2}{*}{$\begin{array}{l}\text { No. of occupants } \\
\text { infested by } \\
\text { head lice }\end{array}$} & \multirow{2}{*}{$\begin{array}{l}\text { No. of } \\
\text { collected } \\
\text { head lice }\end{array}$} & \multirow{2}{*}{$\begin{array}{c}\text { Prevalence } \\
(\%)\end{array}$} & \multicolumn{2}{|c|}{ Clades } \\
\hline & & & & & & & A & $\mathrm{C}$ \\
\hline 1 & Selayang & Madrasah Hashimiah & 99 & 16 & 83 & 16.2 & 65 & 18 \\
\hline 2 & Puchong & United Arakan Institute Malaysia & 63 & 6 & 31 & 9.5 & 4 & 27 \\
\hline 3 & Cheras & Ahmadiah Refugee Committee & 56 & 1 & 2 & 1.8 & 0 & 2 \\
\hline 4 & Kajang & Al-Islamiah Centre & 39 & 39 & 17 & 23.1 & 5 & 12 \\
\hline 5 & Sungai Buloh & Tahfiz Sri Al-Ain & 78 & 78 & 34 & 19.2 & 26 & 8 \\
\hline
\end{tabular}

Current data on the genetic variation of $\mathrm{COI}$ of head lice in Malaysia are scarce and to our knowledge, only one such study was conducted by Mokhtar et al. (2019). Our finding is the first to demonstrate the occurrence of clade $C$ head lice in Malaysia, amongst the clade A collected from the shelter homes in Klang Valley. The NJ cluster analysis based on $\mathrm{COI}$ barcodes has successfully showed the phylogenetic placement of the 167 head lice into two BINs of clades A and C. The detection of clade A lice in this study further confirmed its global distribution. Clade $\mathrm{C}$ was previously detected in head lice from Nepal and Africa (Light et al., 2008a). In 2015, Sunantaraporn et al. (2015) first reported the occurrence of clade $C$ in Southeast Asia. Data in this study shows that both clade $A$ and $C$ occur in sympatry. Concurrent occurrence of clades $A$ and $C$ was also reported in Thailand (Sunantaraporn et al., 2015), Ethiopia (Angelakis et al., 2011; Veracx et al., 2013) and Senegal (Boutellis et al., 2012). Clade A comprises both head and body lice whereas clade $C$ comprises only head lice (Light et al., 2008b; Drali et al., 2016). Both clades have been shown to carry pathogens, therefore, addressing the clade diversity is fundamental to provide insight into the transmission dynamics of their potential associated pathogens in Malaysia setting. Despite the low prevalence of pediculosis capitis encountered in the current study, the data obtained provide baseline data useful for the relevant authorities including health and welfare departments to work on necessary planning, funding and control strategies to prevent the occurrence of pediculosis capitis especially in children welfare institutions. It is anticipated that $\mathrm{CO}$ I DNA barcoding has revealed the genetic diversity of head lice in Malaysia where sympatricity of clades $A$ and $C$ offers tremendous scope for extensive studies, especially on the potential associated pathogens these two clades might carry.

\section{ACKNOWLEDGEMENTS}

This study was financially supported by the Ministry of Higher Education, Malaysia (Higher Institution Centre of Excellence Program, Project MO002-2019) and Impact Oriented Interdisciplinary Research Grant (IIRG002A-2020SAH). Most importantly, we thank the welfare homes' residents who have participated in this study.

\section{Conflict of interest statement}

The authors declare that they have no competing interest.

\section{REFERENCES}

Abd Majid, M.A., Khoo, J.J., Lim, F.S., Khor, C.S., Loong, S.K., Low, V.L., Lee, H.Y. \& AbuBakar, S. (2020). Bacterial profiling of head lice isolated from the Orang Asli: A first report in Malaysia. Tropical Biomedicine 37: 884-895. https://doi.org/ 10.47665/tb.37.4.884
Amanzougaghene, N., Akiana, J., Mongo Ndombe, G., Davoust, B., Nsana, N.S., Parra, H.J., Fenollar, F., Raoult, D. \& Mediannikov, O. (2016). Head lice of pygmies reveal the presence of relapsing fever borreliae in the Republic of Congo. PLoS Neglected Tropical Diseases 10: e0005142. https:/ /doi.org/10.1371/journal.pntd.0005142

Angelakis, E., Diatta, G., Abdissa, A., Trape, J.F., Mediannikov, O., Richet, H. \& Raoult, D. (2011). Altitude-dependent Bartonella quintana genotype $\mathrm{C}$ in head lice, Ethiopia. Emerging Infectious Diseases 17: 2357-2359. https://doi.org/ 10.3201/eid1712.110453

Bachok, N., Nordin, R.B., Awang, C.W., Ibrahim, N.A. \& Naing, L. (2006). Prevalence and associated factors of head lice infestation among primary schoolchildren in Kelantan, Malaysia. The Southeast Asian Journal of Tropical Medicine and Public Health 37: 536-543.

Bonilla, D.L., Kabeya, H., Henn, J., Kramer, V.L. \& Kosoy, M.Y. (2009). Bartonella quintana in body lice and head lice from homeless persons, San Francisco, California, USA. Emerging Infectious Diseases 15: 912-915. https://doi.org/ 10.3201/eid1506.090054

Boutellis, A., Mediannikov, O., Bilcha, K.D., Ali, J., Campelo, D., Barker, S.C. \& Raoult, D. (2013). Borrelia recurrentis in head lice, Ethiopia. Emerging Infectious Diseases 19: 796798. https://doi.org/10.3201/eid1905.121480

Boutellis, A., Veracx, A., Angelakis, E., Diatta, G., Mediannikov, O., Trape, J.F. \& Raoult, D. (2012). Bartonella quintana in head lice from Sénégal. Vector-Borne and Zoonotic Diseases 12: 564-567. https://doi.org/10.1089/vbz.2011.0845

Bouvresse, S., Socolovshi, C., Berdjane, Z., Durand, R., Izri, A., Raoult, D., Chosidow, O. \& Brouqui, P. (2011). No evidence of Bartonella quintana but detection of Acinetobacter baumannii in head lice from elementary schoolchildren in Paris. Comparative Immunology, Microbiology and Infectious Diseases 34: 475-477. https://doi.org/10.1016/ j.cimid.2011.08.007

Drali, R., Mumcuoglu, K.Y. \& Raoult, D. (2016). Human lice in paleoentomology and paleomicrobiology. Microbiology Spectrum 4. https://doi.org/10.1128/microbiolspec.PoH0005-2014

Falagas, M.E., Matthaiou, D.K., Rafailidis, P.I., Panos, G. \& Pappas, G. (2008). Worldwide prevalence of head lice. Emerging Infectious Diseases 14: 1493-1494. https://doi.org/ 10.3201/eid1409.080368

Hall, T.A. (1999). BioEdit: a user-friendly biological sequence alignment editor and analysis program for Windows 95/ 98/NT. Nucleic Acids Symposium Series 41: 95-98.

Kempf, M., Abdissa, A., Diatta, G., Trape, J.F., Angelakis, E., Mediannikov, O., La Scola, B. \& Raoult, D. (2012). Detection of Acinetobacter baumannii in human head and body lice from Ethiopia and identification of new genotypes. International Journal of Infectious Diseases 16: e680-e683. https://doi.org/10.1016/j.ijid.2012.05.1024 
Kumar, S., Stecher, G., Li, M., Knyaz, C. \& Tamura, K. (2018). MEGA X: molecular evolutionary genetics analysis across computing platforms. Molecular Biology and Evolution 35: 1547-1549. https://doi.org/10.1093/molbev/msy096

Light, J.E., Allen, J.M., Long, L.M., Carter, T.M., Barrow, L., Suren, G., Raoult, D. \& Reed, D.L. (2008a). Geographic distribution and origins of human head lice (Pediculus humanus capitis) based on mitochondrial data. Journal of Parasitology 94: 1275-1281. https://doi.org/10.1645/GE1618.1

Light, J.E., Toups, M.A. \& Reed, D.L. (2008b). What's in a name: The taxonomic status of human head and body lice. Molecular Phylogenetics and Evolution 47: 1203-1216. https://doi.org/10.1016/j.ympev.2008.03.014

Mokhtar, A.S., Lau, Y.L., Wilson, J.-J. \& Abdul-Aziz, N.M. (2019). Genetic diversity of Pediculus humanus capitis (Phthiraptera: Pediculidae) in Peninsular Malaysia and molecular detection of its potential associated pathogens. Journal of Medical Entomology 57: 915-926. https://doi.org/ 10.1093/jme/tjz234

Muhammad Zayyid, M., Saidatul Saadah, R., Adil, A.R., Rohela, M. \& Jamaiah, I. (2010). Prevalence of scabies and head lice among children in a welfare home in Pulau Pinang, Malaysia. Tropical Biomedicine 27: 442-446.

Nutanson, I., Steen, C.J., Schwartz, R.A. \& Janniger, C.K. (2008). Pediculus humanus capitis: an update. Acta dermatovenerologica Alpina, Pannonica, et Adriatica 17: 147-159.

Ratnasingham, S. \& Hebert, P.D. (2013). A DNA-based registry for all animal species: The barcode index number (BIN) system. PLOS ONE 8: e66213. https://doi.org/10.1371/ journal.pone.0066213
Sasaki, T., Poudel, S.K., Isawa, H., Hayashi, T., Seki, N., Tomita, T., Sawabe, K. \& Kobayashi, M. (2006). First molecular evidence of Bartonella quintana in Pediculus humanus capitis (Phthiraptera: Pediculidae), collected from Nepalese children. Journal of Medical Entomology 43: 110-112. https://doi.org/10.1093/jmedent/43.1.110

Sinniah, B., Sinniah, D. \& Rajeswari, B. (1981). Epidemiology of Pediculus humanus capitis infestation in Malaysian school children. The American Journal of Tropical Medicine and Hygiene 30: 734-738. https://doi.org/10.4269/ajtmh. 1981.30.734

Sinniah, B., Sinniah, D. \& Rajeswari, B. (1983). Epidemiology and control of human head louse in Malaysia. Tropical and Geographical Medicine 35: 337-342.

Sunantaraporn, S., Sanprasert, V., Pengsakul, T., Phumee, A., Boonserm, R., Tawatsin, A., Thavara, U. \& Siriyasatien, P. (2015). Molecular survey of the head louse Pediculus humanus capitis in Thailand and its potential role for transmitting Acinetobacter spp. Parasites \& Vectors 8: 127. https://doi.org/10.1186/s13071-015-0742-4

Veracx, A., Boutellis, A. \& Raoult, D. (2013). Genetic recombination events between sympatric Clade $A$ and Clade $C$ lice in Africa. Journal of Medical Entomology 50: 1165-1168. https://doi.org/10.1603/me13028

Yap, F.B., Elena, E.M. \& Pubalan, M. (2010). Prevalence of scabies and head lice among students of secondary boarding schools in Kuching, Sarawak, Malaysia. The Pediatric Infectious Disease Journal 29: 682-683. https://doi.org/ 10.1097/INF.0b013e3181df61dd 